\title{
Venancio Fortunato y sus relaciones con los obispos de la Galia en el contexto del siglo VI
}

\author{
Venantius Fortunatus and his relations with the bishops of Gaul in the context of the sixth \\ century
}

(4iliana Pégolo

Universidad de Buenos Aires, Argentina

Fecha de recepción: septiembre de 2018. Fecha de aceptación: octubre de 2018.

\begin{abstract}
Resumen
Venancio Fortunato fue un viritalus, nacido cerca de Treviso (ca. 530-540), que se convirtió en un modelo de comportamiento para las élites del siglo VI. En su travesía como poeta "itinerante" por los territorios merovingios, contó con su formación retórico-literaria para relacionarse con soberanos, aristócratas, hombres y mujeres de la Iglesia.

De los carmina dedicados a numerosos clérigos, analizaremos algunos compuestos a Leoncio de Bordeaux, Félix de Nantes y Gregorio de Tours, que demuestran la capacidad de Fortunato para forjar relaciones de amicitia en diversos planos políticos, a la vez que se exhiben como un "observatorio" privilegiado de la transición entre el Tardoantiguo y el Medioevo.
\end{abstract}

\footnotetext{
Abstract

Venantius Fortunatus was a viritalus, born near in Treviso (ca. 530-540 AD), who became a model of behavior for the elites of the sixth century. In his journey as an "itinerant" poet through the Merovingian territories, he counted on his rhetoricalliterary training to relate with sovereigns, aristocrats, men and women of the Church.

About the Carmina dedicated to numerous clerics, we will analyze some compounds to Leontius of Bordeaux, Felix of Nantes and Gregorius of Tours, they which demonstrate the ability of Fortunatus to forge amicitia' relations at various political levels, while being exhibited as an "observatory" privileged of the transition between the Late Antiquity and the Middle Ages.
}

\section{Palabras clave}

obispos

Venancio Fortunato Galia merovingia poesía encomiástica

\section{Keywords}

bishops

Venantius Fortunatus Merovingian Gaul laudatory poetry 


\section{Venancio Fortunato, vir Italus y poeta itinerante}

1. La dedicatoria del primer libro de poemas a Gregorio de Tours dice lo siguiente: Domino sancto et dote merotorum sacris altaribus adscito et educto Gregorio Papae Fortunatus (“Fortunato al papa Gregorio, señor santo, y por el don de sus méritos recibido en igual medida y elevado a los sagrados altares").

2. Roberts (2012 [2009]: 5) sostiene que la fecha de nacimiento del poeta fue el año 530.

3. Cf. Bodelón (2013-2014: 99). El autor afirma que en Ceneta había un antiguo castellum (continúa en página 21)

4. La denominación de Duplavilis aparece, entre otros artículos, en el de Bodelón y en el de Pejenaute Rubio (2004: 193); en el resto de las referencias críticas consultadas se nombra a la ciudad como Duplavis.

5. La ciudad de Valdobbiadene se encuentra, entre otras de la región,

a $58 \mathrm{~km}$. de Venecia y a $32 \mathrm{~km}$. de

la ciudad de Treviso, capital de

la provincia del mismo nombre.

6. En torno de esta región del nor-

te de Italia, se señala que Ceneta

fue una de las localidades devasta-

das por Atila en su arremetida (continúa en página 21)

7. La Vía Claudia Augusta, la mayor de las viae llevadas a cabo por los romanos, atraviesa los Alpes, comunicando la zona de la desembocadura del Po y la región rética, es decir, desde el Adriático hasta el curso alto del río Danubio.

8. En la dedicatoria a Gregorio de Tours (Praef. 5) Fortunato afirma: novus Orpheus lyricus silvae voces dabam, silva reddebat ("yo como un nuevo Orfeo lírico daba voces al bosque [y] el bosque me las devolvía.").

9. Pejenaute Rubio (2004: 205) afirma que, según lo señalado por parte de la crítica, el itinerario (continúa en página 21)

10. Particularmente el poema que inaugura el L. I está dedicado a Vital (continúa en página 21)

11. En la primavera del año 566 se encuentra en la ciudad de Metz con motivo de las bodas del rey de Austrasia, Sigiberto

12. En la ciudad de París habría permanecido durante el invierno, cf. Pejenaute Rubio (2004: 205).

13. La autora señala que, bajo el Imperio, las orationes de agradecimiento que durante la República romana (continúa en página 21)

14. Fort., 3.9.45-46: Si tibi nunc avium resonant virgulta susurro,

I has inter minimus passer amore cano. (continúa en página 21)
Venancio Fortunato, conocido como Fortunato,-ya que así se dirige en la dedicatoria de su obra al obispo Gregorio de Tours $-{ }^{1}$, se llamaba en realidad Venantius Honorius Clementianus Fortunatus y habría nacido entre los años $530^{2}$ y 540, en la región del Véneto; según señalan los críticos, ${ }^{3}$ su lugar de origen sería la antigua ciudad de Duplavis o Duplavilis, ${ }^{4}$-la moderna Valdobbiadene ${ }^{5}$-, ubicada en las proximidades de Ceneta ${ }^{6}$ cerca de Treviso, donde se hallaba la Via Claudia Augusta. ${ }^{7}$ Allí, su familia de terratenientes habría vivido por generaciones (cf. Pucci, 2010: xix), aunque no se sabe con certeza si pertenecía a la aristocracia (cf. Jones, 2009: 44); al respecto, Reydellet sostiene que Fortunato era un aristócrata, cuya posición social le permitió adquirir una formación académica en las escuelas de gramática y de retórica de Rávena, lo que habría de facilitarle posteriormente el ejercicio de su vocación poética (Reydellet, 2002: VIII).

Este auto-calificado novus Orpheus lyricus, ${ }^{8}$ que dejó su tierra natal por razones de salud o, como advierte parte de la crítica, alejándose de las luchas que opusieron el ejército gótico al imperial (cf. La Rocca, 2005: 146) o bien tan solo buscando fortuna como "un bardo errante" (cf. Pejenaute Rubio, 2004: 213), se encaminó en el año 565 hacia el santuario de Martín de Tours. ${ }^{9}$ Sólo dos poemas escribió Fortunato en tierra italiana, dirigidos al obispo Vital de Rávena que había construido una iglesia en honor de san Andrés, hermano del apóstol Pedro. ${ }^{10}$ En los siguientes diez años, desde que se produjo su arribo a la Galia en el $566^{11}$ hasta el 576,--posiblemente habría llegado con cartas de recomendación del episcopado del norte de Italia dirigidas a su contraparte gala (cf. George, 1998: 227) -, desarrollaría una intensa labor literaria, dedicada a sus numerosos amigos y "patronos" en tierras de los francos, quienes, en época de Fortunato, deben considerarse a aquellos poderosos que reconocían la supremacía de los reyes merovingios (cf. La Rocca, 2005: 147). Como sostiene Wood, la obra poética de Fortunato, que incluye numerosas epístolas en verso y algunas en prosa, poesías de alabanza, un epitalamio, en el que celebra el matrimonio del rey Sigiberto y la princesa visigótica Brunilda, y una reconocida producción hagiográfica e hímnica, constituye "la mejor evidencia de la ideología de la corte merovingia en la segunda mitad del siglo VI" (Wood, 1994: 27).

Después de haber dejado atrás la corte de Sigiberto, la cercanía con los obispos del reino de Austrasia y, en particular, el encuentro con Germán, obispo de París, ciudad a la que había arribado en otoño del año 566, ${ }^{12}$ halló finalmente en Poitiers, en el 568, su lugar definitivo junto a la princesa turingia Radegunda, viuda del rey Clotario I, quien había fundado el convento de la Santa Cruz. Ella, como amiga y domina, sería, hasta su muerte -ocurrida en 587-, una figura sumamente importante en torno del Fortunato-poeta, que ya se había convertido en un "recurso" apreciado para los potentiores de su época (cf. Roberts, 2012: 7). Cabe señalar que en su poesía se advierten las características de la producción panegírica que tanto había satisfecho a las cortes imperiales de los siglos anteriores como expresión oficial de alabanza (laudatio) y agradecimiento (actio gratiarum) de las acciones de los emperadores (cf. Ware, 2012: 22). ${ }^{13}$ Llamándose a sí mismo minimus passer, ${ }^{14}$ Fortunato encontró en el género de la laudatio una herramienta útil para poner en evidencia el entrenamiento retórico recibido; este resultaría sumamente efectivo para el desarrollo de la compleja comunicación existente con sus "patronos", la cual reproducía las negociaciones que se llevaban a cabo entre el poder político y el eclesiástico (cf. George, 1998: 225). 


\section{Algunas consideraciones sobre los officia episcopales}

Entre los numerosos receptores de Fortunato que pertenecen al clero, la crítica destaca en particular a tres por el hecho de ser los destinatarios de un pequeño dossiers de composiciones (cf. Roberts, 2017: x): estos son los obispos Leoncio de Bordeaux, Félix de Nantes y Gregorio de Tours, quienes, como en la mayoría de los textos compuestos a funcionarios de la Iglesia - sean estos de mayor o menor importancia-, son objeto de alabanza a causa de sus virtudes caritativas, predicación y dedicación a la construcción y reacondicionamiento de los espacios eclesiales (Roberts, 2017: x). Tal como señala Hamman, en una descripción panorámica de los aspectos más sobresalientes del siglo IV, las tareas del obispo eran diversas por el peso social que desempeñaba en la comunidad, ya que

\section{El patrimonio de la Iglesia crece, sus necesidades aumentan y se diversifican. Ante las carencias del poder civil, el obispo debe ocuparse de la ciudad, defender los intereses de los ciudadanos, intervenir ante la justicia secular, mitigar el rigor de la ley, mejorar la condición de los presos e impetrar la reducción o el aplazamiento de los impuestos. (Hamman, 1986: 16)}

No obstante, en el contexto del período merovingio según el análisis de Wood, la autoridad de la Iglesia y particularmente la de los obispos estaba conectada al poder del rey, en especial en los centros urbanos del reino franco. En cuanto a la estructura de la Iglesia merovingia, esta evocaba a sus antecesores galo-romanos en lo que respecta a la organización de las diócesis, que no siempre se correspondía con la geografía de las civitates de cuño romano, sobre todo tras las invasiones acaecidas durante el siglo V. Por razones políticas el rey podía impedir que el obispo actuara en determinadas ocasiones en relación con las solicitudes de su comunidad; sin embargo, cuando el reino de los francos (regnum Francorum) se convirtió en un estado cristiano tras el bautismo del rey Clovis, ocurrido en el año 508, se retorna en muchos aspectos a la situación que detentaba la autoridad episcopal hacia finales del siglo IV (cf. Wood, 1994: 71-72).

Si bien en los textos de Fortunato no reconoceremos muchas de las tareas que se enumeraron en párrafos anteriores, no deja de ser significativo el hecho de que se destaque la incumbencia económica de los obispos en la construcción de iglesias, como un instrumento para alcanzar la consolidación terrenal de su potentia aristocrática (cf. Jones, 2009: 337), y la tendencia a monopolizar los centros locales donde se hallaban reliquias de mártires y otros objetos de devoción, los cuales pasaban a convertirse en focos de poder religioso y de autoridad espiritual (Wood, 1994: 73-74). ${ }^{15}$ Asimismo, en algunos de las composiciones, es posible visualizar la pertenencia de estos funcionarios a las élites de los potentiores y, por lo tanto, el establecimiento de redes de influencia y amicitia, ${ }^{16}$ con las consecuentes rencillas y pactos de solidaridad surgidos a partir de los roles sociales que estos desempeñaban (cf. La Rocca, 2005: 148).

\section{El labor poético de Fortunato: alabanza a sus "patronos" epis- copales}

Comenzaremos por los poemas dedicados a Leoncio de Bordeaux, ${ }^{17}$ ya que la mayoría de estos se hallan en el liber inicial de la obra de Fortunato, la cual comprende un total de once libros. ${ }^{18}$ De los catorce carmina incluidos en él, siete son epigramas celebratorios de la construcción y restauración de iglesias llevadas a cabo por el obispo (1.6 y 1.8-13), dos son panegíricos convencionales, en los que se continúa con la tradición desarrollada, entre otros poetas, por Claudio Claudiano (ss. IV-V) y
15. Previamente el autor incluye, entre las tareas de las que se ocupaban los obispos, la regulación de la vida matrimonial de los reyes y la de circunscribir las actividades de la comunidad judía, que era reconocida como una minoría religiosa en el reino. 16. Wood (1994: 27) afirma que Fortunato opta a menudo por el término dulcedo antes que usar amicitia. Como advierte Levine, R. (2008: 81-82), este vocabulario es de carácter "amoroso", lo que debe ser comprendido dentro de los límites de una práctica social y cortesana, la cual se vincula a la autoridad de los poderosos y a los términos de armonía social que este poder produce.

17. Conocido como Leoncio el Joven o II, por haber sucedido a otro obispo de nombre Leoncio, al que se lo suele llamar el Viejo o Leoncio I. A este último, Fortunato le dedica un epitafio, el 4.9, y a su sucesor el siguiente, el 4.10. Roberts (2017: 856) afirma que Leoncio I concurrió al Concilio de Orleans en el año 541 y que su muerte se habría producido en 552 . Leoncio II asume entonces hasta el 570. La relación entre ambos resulta desconocida. Según Jones (2009: 47), Leoncio II se habría desempeñado como obispo entre los años 549 y 573 . Como recuerda George (1998: 233), Leoncio había desarrollado una importante carrera militar hasta que asumió el obispado, quizás heredado de su padre; era un aristócrata perteneciente a una familia senatorial de cuño romano, de gran ambición política que también supo entrar en disputa con el rey Cariberto, hacia el 560 y con algunos obispos, tal como lo demuestra el carmen 1.12.3-6.

18. A estos once libros hay que sumarles un Appendix constituido por una treintena de poemas, entre los cuales se incluyen algunas epístolas. 
19. Este metro es el utilizado por Ambrosio en sus himnos y por Prudencio en los dos poemas iniciales y los dos finales de Cathemerinon.

20. Según señala Wood (1994: 84), Leoncio era nieto de Avito, obispo de Clermont.

21. Jones (2009: 47) estima que Fortunato habría transcurrido una placentera estadía junto a Leoncio y su esposa, Placidina. Más adelante, en p. 124, el autor recuerda a esta como heredera de la familia del emperador Eparquio Avito y de Sidonio Apolinar, cuya esposa también se llamaba Placidina. 22. Fort., 1.17.1-2: “[...], piadosa, [...] / que resplandeces tú misma más apareciendo como un don en el orbe".

23. A través de una selección de poemas, se destacan los officia desarrollados por el obispo.

24. Fort. 1.6.4: "porque las cosas buenas que ha hecho, a estas las piensa como sus ganancias".

25. Ibíd. 5-6: "Por lo tanto Leoncio fundó en los campos nutricios santuarios, / a fin de que con tales deberes él mismo entre a los cielos".

26. Jones (2009: 124) afirma que sería posible pensar que el poema estuviera pintado en las paredes de la iglesia para recordar

el plan de sus constructores.

27. Fort. 1.6. 21-22: "Placidina adornó estas eminentes [estructuras] con sagrados cortinados / y como contendientes, al mismo tiempo él hizo la iglesia, ella la ornó."

28. Vicente de Agen, mártir no tan conocido como su homónimo de Zaragoza, fue un diácono cristiano de Gascuña (s. III) que habría intervenido en una ceremonia druida, tras la cual fue apresado y decapitado. En cuanto a la ciudad de Agen, esta se encuentra en la margen derecha del río Garona, perteneciente a

la región de Nueva Aquitania.

29. Fort. 1.8.13-15: "Por el nuevo amor de este [Vicente], Leoncio, completando piadosas ofrendas,

/ entregó techos estañados,

en donde yacen sus miembros sagrados, / y es lícito que brille por sus méritos el venerable templo".
Sidonio Apolinar (s. V): uno muy breve, de cuatro versos, en el que se alaba el cáliz donde Leoncio ofrece sus "piadosos dones" (1.14.1: pia dona) y otro extenso, de ciento diez versos, donde Fortunato exalta la alta potestas del personaje entre "los ciudadanos galos" (1.15.3: civibus ex Gallis); con un tono de alabanza semejante le dedica un himno abecedario, compuesto por noventa y dos dímetros yámbicos acatalécticos (1.16). ${ }^{19}$ A estos poemas se suman otros tres (1.18-20), en los que se describen las villae de las que era propietario el obispo y el paisaje bucólico que las enmarca, lo cual permite establecer cuál era su estatus patrimonial, y la vigilancia, protección y prosperidad que provee a sus fundos este actor social, emparentado con la aristocrática dinastía del obispado de Clermont. ${ }^{20}$ Hay un carmen más, el 1.17, dedicado a la esposa de Leoncio, la episcopa Placidina, ${ }^{21}$ a quien Fortunato se refiere como un don piadoso que brilla en el orbe (vv. 1-2: [...], pia, [...], / quae magis ipsa decens munus in orbe micas. $)^{22}$

Todos los poemas mencionados, que representan el 66.66\% del total del libro, están compuestos en dísticos elegíacos - a excepción del 1.16-, y pertenecen a la antigua tradición epigramática; resulta oportuno destacar que el epigrama, según indica su etimología, remite al género de las inscripciones, es decir, los epigrammata son textos "escritos sobre" diferentes objetos, tales como estatuas, tumbas, e incluso la corteza de los árboles, y se destacan desde su origen por su brevedad, claridad y una focalizada resolución temática. Alrededor del siglo V a. C., comenzó a concretarse su funcionalidad y su forma literaria, explorando temas relacionados con lo funerario, lo simposíaco y lo erótico, y mostrando una fuerte predilección por el uso del dístico (cf. Williams, 2004: 5-6). Fortunato adopta este género y el metro como característica tipológica para celebrar, particularmente, la edificación de una serie de "basílicas", así denominadas por el poeta, las cuales se destacan por lo que Roberts denomina como "las metáforas de la eminencia" (cf. Roberts, 2012: 38 ss.). Entre estas cabe mencionar::23

-De basilica Sancti Martini (1.6: "Acerca de la iglesia de San Martín"). En este poema Fortunato destaca el hecho de "quien desea asociarse con los bienaventurados en la sede eterna" (v. 1: Qui cupit aeterna sociari in sede beatis) y lo "hace a través de piadosas ofrendas" (v. 2: per pia vota facit) que funcionan como ganancias lucrativas a futuro (v. 4: cum bona quae dederit haec sua lucra putet).$^{24}$ Esta es la finalidad de la fundación de un espacio sagrado, al que el poeta califica de "nutricio", como parte de los deberes de Leoncio para asegurarse la entrada a los cielos (vv. 5-6: Condiditergo arvis delubra Leontius alma, / talibus officiis intret ut ipse polos). ${ }^{25}$ En particular no nos detendremos en el análisis de la figura de Martín de Tours a la que se destaca por el fulgor de sus méritos luchando contra la guerra y la lepra (vv. 7-10), de ahí que se justifique el hecho de erigir un templo que lo evoque ocasionalmente en Bordeaux (vv. 11-14); sólo destacaremos los versos finales del poema, en los cuales, a la manera de una inscripción, ${ }^{26}$ Fortunato exalta junto al obispo a la figura de su esposa Placidina como la mentora de la ornamentación del templo (vv. 21-22: Quae Placidina sacris ornavit culmina velis, / certantesque simul hic facit, illa colit). ${ }^{27}$

-De basilica Sancti Vincenti ultra Garonnam (1.8: "Acerca de la iglesia de San Vicente más allá del Garona"). Este carmen está dedicado a la figura del mártir en cuyo honor se yergue la iglesia. Fortunato, valiéndose de tópicos estereotipados como el del triunfo sobre la muerte y su ascenso hacia las estrellas tras un nuevo nacimiento (7-8), evoca el sacrificio del mártir, quien fue decapitado y así alcanzó el cielo (10-12). Se trata de Vicente de Agen, ${ }^{28}$ cuyas reliquias se encuentran en el templo por intermediación del propio obispo, que contribuye a sostener el espacio sacro con su donación:

Huius amore novo pia vota Leontius explens, quo sacra membra iacent, stagnea tecta dedit, et licet eniteat meritis venerabile templum, (vv. 13-15) 29 
De manera semejante a estos poemas, Fortunato alaba la fundación de otro templo dedicado a Vicente (1.9) y el reacondicionamiento de la iglesia de los mártires Nazario (1.10) y Dionisio, el obispo parisino, ${ }^{30}$ a quien también se habría erigido un templo en Bordeaux, en una de las propiedades del obispo (1.11). Por otra parte Leoncio y su esposa, abocados en un programa de construcción y reconstrucción de iglesias, fueron los propiciadores del culto de Bibiano, quien fue obispo de la ciudad de Saintes, en el siglo $V^{31}$ (1.12) y de Eutropio, el primero en ocupar el episcopado de esta misma ciudad, la antigua Santonica (1.13.19), cuyas reliquias se encuentran resguardadas en un templo sumamente ornamentado. ${ }^{32}$

En lo que respecta a Félix de Nantes, ${ }^{33}$ a quien Fortunato compara con Salomón, 34 el poeta le dedica siete carmina (3.5-10 y 5.7), 35 y una extensa carta en prosa (3.4), donde exalta hiperbólicamente la brillantez y profundidad de su elocuencia:

Tantus enim exercitati claritate colloquii vestrae linguae iubar effulsit, tanta se renidentis eloquentiae lux vibravit, ut converso ordine mihi videretur verbis radiantibus ab occidentali parte te loquente sol nasci. (3.4.2) $3^{36}$

Mientras Wood destaca a Félix por contar con un programa de construcción de iglesias (Wood, 1994: 76), Roberts señala que el poeta evoca la cercanía existente con la región de Bretaña, acostumbrada a los "raids" de los britanos y por la labor evangelizadora llevada a cabo por el obispo en la conversión de numerosos sajones infieles, cosa que es poetizada por Fortunato en el lenguaje característico de la alegoría eclesiológica (Roberts, 2012: 51-52). Asimismo el crítico afirma que la descripción del interior de la catedral, que Félix hizo construir en Nantes (3.7), es la más completa en lo que se refiere a la decoración y a su estructura arquitectónica, adecuada para contener numerosas reliquias de mártires. ${ }^{37}$

A causa de la extensión de los poemas dedicados a Félix, nos detendremos tan solo en dos de ellos, en el primero y el último de la serie del libro tercero: el 3.5 (Item ad Felicem episcopum ex nomine suo $)^{38}$ es un breve carmen, compuesto por cinco pares de dísticos elegíacos, que resulta singular porque se trata de un acróstico; en él se representa el nombre del poeta, quien imprime su "firma" lúdicamente en un panegírico de tópicos tradicionales, ya que se exalta al obispo llamándolo "confiada salvación de la patria" (v. 1: Fida salus patriae), "orden de los sacerdotes" (v. 2: Ordo sacerdotum), "voz de los próceres, luz de su familia, defensa de la plebe" (v. 5: Vox procerum, lumen generis, defensio plebis), "decoro de la patria, luz de la fe, acrecentador del honor" (v. 9: decus patriae, fidei lux, auctor honoris) y, para terminar, "esplendor de los pontífices, amor nuestro y del orbe" (v. 10: Splendor pontificum, noster et orbis amor.).

Como puede advertirse, Fortunato hace gala de la tradición poética en la que se ha formado, ya que se advierten en el poema "voces" procedentes de la literatura clásica; tan solo hay dos versos que remiten a situaciones contemporáneas al poeta y a su receptor, ya que se reconoce al obispo venciendo sobre los britanos que solían asolar las costas, de ahí que se lo llame: "conductor apostólico que, venciendo los derechos británicos, / seguro en las adversidades, haces huir las armas con la esperanza de la cruz" (vv. 7-8: Actor apostolicus qui iura Britannica fugas, / Tutus in adversis, spe crucis arma fugas.). Félix, entonces, desde la mirada exaltada del agradecido Fortunato, no solo es, según la inspiración horaciana, ${ }^{39}$ el "puerto" que prohíbe el naufragio (v. 6: Naufragium prohibes hic ubi portus ades $)^{40}$, sino también a la manera ciceroniana hace que las armas cedan, en este caso no ante la toga consular, sino ante la cruz episcopal. ${ }^{41}$

En cuanto al poema 3.10, titulado De domno Felice Namnetico, cum fluvium alibi detorqueret ("Acerca del Señor Félix de Nantes, como torciera el río en otro lugar"),
30. Se trata de San Denis, el apóstol de las Galias o también conocido como el "obispo sin cabeza", martirizado en una persecución anterior a la ordenada por el emperador Diocleciano.

31. En esa ciudad habría nacido Leoncio, en 510.

32. Fort. 1.13.17: Sumpsit imagineas paries simulando figuras: ("La pared asumió figuras imitando imágenes") 33. Destacado administrador, según la opinión de Wood (1994: 76), Félix fue obispo de Nantes entre los años 549 y 582 . Acerca de la hospitalidad dada al poeta por parte del obispo, Roberts (2012: 23-24) advierte que puede deberse al hecho de que su padre, el obispo Eumerio, habría recibido en otra ocasión a Fortunato, quien agradeció a través de diversos encomia por haberse apiadado de su condición de peregrinus y exul.

34. Fort., 3.6.1-2: Cum Salomon coloret generosi encaenia templi I Israhel electos fecit adesse viros ("Como Salomón celebrara la dedicatoria de su templo generoso / hizo que estuvieran presentes los principales varones de Israel"). Cf. Jones (2009: 32).

35. Los poemas dedicados al obispo Félix, que se encuentran incluidos en el Libro III, están escritos en dísticos elegíacos; en cambio la composición incluida en el Libro V está compuesta en hexámetro dactílico.

36. Fort., 34.2: "Pues tanto resplandor de tu lengua refulgió en la ejercitada claridad de tu discurso, tanta luz de tu elocuencia resplandeciente vibró, que una vez completado el orden de su curso me pareció que el sol nacía desde Occidente por tus palabras radiantes, cuando tú hablabas."

37. Ibíd., 66-68. El crítico se detiene en el análisis de las particularidades de la planta catedralicia, en las figuras representadas que funcionan como ornamento, destacando de manera singular el juego de luces y de cromatismos, que estaría inspirado en la poesía prudenciana.

38. El título del poema se refiere al propio Fortunato al decir: "Lo mismo para el obispo Félix a partir de su propio nombre".

39. Posible intertextualidad con la oda I.14.2-3 de Horacio: Fortiter occupas / portum ("Con fuerza ocupa / el puerto.”).

40. Fort., 3.5.6: "Prohíbes aquí el naufragio cuando estás presente como un puerto."

41. Se hace referencia al hexámetro ciceroniano incluido en De officiis 1.22.77: cedant arma togae, concedat laurea laudi ("Cedan las armas a la toga, conceda el laurel a la alabanza”). 
42. Fort., 3.10.5: “Todos en conjunto leerían a Félix sin restricciones, ninguno a Aquiles,").

43. Ibíd., 21-22: "Las aguas, que antes corrían al revés, así como sin dar fruto, / ahora ofrecen su servicio para sustento de la plebe."

44. Ibíd. 24: "porque a través tuyo la corriente ha aportado alimento al pueblo".

45. Ibíd. 27: "Permanezca para ti,

Félix, una vida piadosa a través del tiempo, sin desmayos."

46. Ibíd., x-xi.

47. Fort., 8.19.7: “Te doy las gracias, querido, por el fruto repleto de tu piedad". / En el poema siguiente, el 20, insiste en su agradecimiento (v. 13: Nec tantum reddo quantum tibi debeo, praesul ["Ni te devuelvo cuanto te debo, buen obispo"]). Observación: Se sigue

la traducción de Roberts (2017: 550) para el término praesul.

48. Fort., 9.6.1: Pollente eloquio pervenit epistula cursu ("Tu carta, de poderosa elocuencia, hizo su curso"); 9.7.1-2: Corde iucundo, calamo venusto / litteras mittis cupiente voto (“Con el corazón feliz, con una encantadora pluma / me envías cartas con un ruego deseoso").

49. Fort. 5.3.1-2: "Aplaudid, pueblos felices, porque son poseedores de nuevas ofrendas,

/ devolved a Dios estos favores por la venida de vuestro obispo."

5o. Ibíd., 3: "Niño sobresaliente, curvada vejez"; 4: "todo hombre".

51. En cuanto a esta alabanza, Roberts (2017: 859-86o) advierte que Fortunato efectúa un juego etimológico de difícil traducción entre el nombre del obispo Gregorius que está en cercanía del sustantivo gregis.

52. Julián de Brioude es un mártir que vivió en el siglo IV, perteneciente a la región de Auvergne; su labor pastoral se focalizó en

la pequeña villa de Brioude, aunque él era natural de Vienne, donde Fortunato tenía su fundo, recibido de la generosidad de Gregorio. Por otra parte estaba relacionado con el aristocrático obispado de Clermont.

53. Fort., 5.3.11-12: “A Martín envía Julián su propio alumno / y a su hermano ofrece lo que fue dulce para él."

54. Fortunato alaba la figura del obispo como perseguidor de herejías en el poema 3.15.

55. Fort., 5.3.13: “A este, la mano nutricia del padre Egidio lo consagró a Dios". se toma en consideración un hecho que para el propio Fortunato resulta sorprendente por sus alcances épicos, lo que ameritaría que "los antiguos poetas" (v. 1: antiqui [...] poetae) y el propio Homero (v. 3: Homerus) lo evocaran. La gran obra de Félix cantada por los vates de la epopeya oscurecería al mismo Aquiles, a quien nadie leería (v. 5: Cuncti Felicem legerent modo, nullus Achillem). ${ }^{42}$ La hipérbole laudatoria alcanza el clímax a causa de la acción transformadora del curso de un río ordenada por el obispo, en beneficio de sus feligreses. La finalidad de tal obra es mejorar el riego hacia los campos que antes carecían de agua y poner la corriente fluvial al servicio de los campesinos (vv. 21-22: Quae prius in praeceps veluti sine fruge rigabant / ad victum plebis nunc famulantur aquae.). ${ }^{43} \mathrm{~A}$ través de los recursos del panegírico se visualiza el tipo de prácticas político-económicas que conformaban las labores episcopales, como la de contribuir al abastecimiento del pueblo (v. 24: cum per te populo parturit unda cibum.). ${ }^{44}$ Esta es la causa de la retribución del poeta que concluye glorificando al obispo para que su vida piadosa permanezca sin desmayos a través del tiempo (v. 27: Stet sine labe tibi, Felix, pia vita per aevum). ${ }^{45}$

Por último, nos referiremos a la figura de Gregorio de Tours, quien ocupa un rol diferente con respecto a las otras dos figuras episcopales, pues se trata de un verdadero "patrono literario" (cf. Roberts, 2017: xi). A él Fortunato dedicó numerosos poemas de carácter epistolar $(5.8-17,8.11-21,9.6$ y 9.7, 10.12 a), aunque no se advierte en todos ellos el tono encomiástico que, según Roberts, aparece de manera definitiva en la composición que celebra la asunción de Gregorio al episcopado de Tours, —acaecida en el año 573-, con la cual el poeta sella su relación con el obispo (5.3). ${ }^{46}$ Esta amicitia se profundizó, a su vez, con la dedicatoria del Libro I y la Vita Sancti Martini, por la cual Fortunato recibió "regalos" por parte de su mentor, incluyendo una pequeña propiedad en las riberas del río Viena, uno de los afluentes del Loire (8.19.7: Grates, care, gero, pietatis fruge repleto). ${ }^{47}$ Asimismo habría sido el propio obispo quien requirió composiciones al poeta, tales como un epigrama que evocaba la restauración de una catedral (10.6) y otros dos poemas, como el 9.6, escrito en dísticos elegíacos, pero anticipando el metro sáfico usado en el siguiente, el 9.7; en ambos se da cuenta de una fluida comunicación epistolar existente entre Gregorio y Fortunato. ${ }^{48}$

De esta nutrida labor poética, con la que buscaba satisfacer a su "patrono", nos detendremos en el poema 5.3, al que Fortunato tituló Ad cives Turonicos de Gregorio episcopo ("A los ciudadanos de Tours, acerca del obispo Gregorio"); en este, en el que sigue la tradición epigramática del uso de los dísticos, se dirige al pueblo como interlocutor para celebrar la llegada de Gregorio, razón por la cual deben dar gracias a la divinidad (vv. 1-2: Plaudite, felices populi, nova vota tenentes, / praesulis adventu reddite vota deo.). ${ }^{49}$ En este acto celebratorio deben participar todos los habitantes de la ciudad, sin distinción de edades (v. 3: puer exertus, curva senectus; v. 4: omnis homo), ${ }^{50}$ ya que ha venido (v. 5: ecce venit) un hombre que encarna todas las virtudes episcopales. En función del propósito encomiástico, en consonancia con la tradición imperial de la actio gratiarum, Fortunato lo alaba llamándolo: "este bien común" (v. 4: hoc commune bonum), "esperanza de la grey", "padre de la plebe", "el que ama a la ciudad", (v. 5: Spes gregis, plebis pater, urbis amator), "pastor de la grey en la ciudad" (v. 10: Gregorius, pastor in urbe gregis). ${ }^{51}$

En la construcción panegírica elaborada por Fortunato, este señala que Gregorio accede al episcopado como parte de la protección que los mártires y santos tributan al pueblo de Tours; por lo tanto es Julián de Brioude, ${ }^{52}$ de quien el obispo y su familia eran devotos, el que entrega a Martín, su hermano, al propio alumno que ha forjado (vv. 11-12: Martino propium mittit Iulianus alumnum / et fratri praebet quod sibi dulce fuit); ${ }^{53}$ asimismo es la "mano nutricia" de Egidio de Reims ${ }^{54}$ el que consagra a Gregorio como su elegido a la divinidad (v. 13: Quem patris Egidii Domino manus alma sacravit). ${ }^{55}$ 
En este sentido se busca renovar o "refundar" al pueblo como fin político-religioso ante la llegada de Gregorio, y lograr la anuencia de otros personajes de importancia como la misma Radegunda (v. 14: ut populum recreet, quem Radegundis amet.). ${ }^{56}$ Pero no basta la protección de los santos, sino que también se requiere del favor de los reyes, por ello es que no falta la mención del monarca Sigiberto de Austrasia y su esposa Brunilda; en definitiva son ellos los que permiten que Gregorio, al que Fortunato denomina nobile culmen, haya alcanzado el episcopado (vv. 15-16: Huic Sigibercthus ovans favet et Brunichildis honori; / iudicio regis nobile culmen adest. $)^{57}$

De lo anterior se desprende que el panegírico aúna los poderes terrenales y celestiales, sin los cuales la acción pastoral del obispo no podría llevarse a cabo; el acontecimiento de la elección de Gregorio debe comprenderse como parte de un plan político del que participan las élites, sean estas laicas o eclesiásticas, ya que resultan interdependientes a la hora de la instalación en los sitios de poder de alguno de sus integrantes. En consecuencia, la descripción que efectúa Fortunato del officium episcopal, adornado según un conjunto de estereotipos retóricos de la hagiografía cristiana, incluye, por lo menos, dos propósitos:

1) ofrecerse como mentor de la laudatio del poderoso, quien como vir Deiy sobre todo como pastor, cuidará a la grey de Cristo (v. 19) para que permanezca "inmaculada", lejos de la contaminación pecaminosa (v. 21), la rapiña (v. 22) y los rabiosos lobos (v. 20), sin abandonar la vigilancia apostólica (vv. 21 y 24), e

2) incluir a Gregorio en la tradición iniciada "bajo la llave de Pedro" y "los dogmas de Pablo" (v. 35), que fue continuada por los Padres de la Iglesia, tales como "el fuerte Atanasio" y "el famoso Hilario" (v. 37), "el rico Martín y el suave Ambrosio" (v. 38), junto con "el sagrado Agustín" (v. 39); tampoco faltan algunos de los Padres Griegos, como Gregorio Nacianceno y Basilio de Cesárea (v.40), todo ellos poderosos obispos y férreos defensores de la ortodoxia nicena.

El cumplimiento de este pacto, al que Fortunato denomina "gesta" (v. 41), permitirá dar cumplimiento a la promesa de alcanzar los dones del Paraíso (v. 18) y las estrellas (v. 32), no solo para el pueblo, sino fundamentalmente para el obispo, al que exalta como miles (v. 44). Cabe destacar, para finalizar, que Fortunato recupera en su hiperbólico encomium las claves de la ficción hagiográfica, por la cual los mártires como milites Christi son intercesores ante la divinidad e inspiran a aquellos que sostienen la fe y, en consecuencia, alcanzan la corona del martirio por los méritos de su labor, ubicándose por encima de los favores terrenales. Este es el ruego para su "patrono" Gregorio con el que concluye el poema (vv. 43-44: atque coronatus digna mercede laborum lobtineat miles Regis in arce locum.). ${ }^{58}$

\section{Conclusiones}

Cristina La Rocca recuerda cómo aún en lo aparentemente pequeño u ocasional, tal como ocurre con algunos de los poemas dedicados a hablar del episcopado de Gregorio, Fortunato sabía hacer uso de su capacidad poética y diplomática para establecer relaciones de poder y de familiaridad con sus receptores, tal como se advierte con la ilustre Placidina (La Rocca, 2005: 149) y los obispos a los que ha gratificado con sus poemas. Este talento para entretejer lazos en diferentes órdenes sociales, lo convirtió en un actor social emergente que supo transparentar en su poesía planos diversos de autoridad monárquica y eclesiástica; a consecuencia de esta doble faz es que Roberts afirma que Fortunato fue un poeta religioso y también un panegirista
56. Ibíd., 14: "para refundar el pueblo, al que Radegunda ama."

57. Ibíd., 15-16: "Sigiberto lo favorece celebrando a este y para honra de Brunilda; / por el juicio del rey una noble eminencia está presente."

58. Ibíd., 43-44: "y coronado como digna retribución a sus esfuerzos / obtenga como soldado un lugar en la ciudadela del Rey." 
59. George (1995: xviii) se refiere a Fortunato como una "figura de dos caras" (“Janus image”).
(Roberts, 2012: 327), cuyos receptores - la corte, los dignatarios de la Iglesia, los hombres y las mujeres de la nobilitas - eran igualados a través de su estilo sofisticado y deudor de la elocutio retórica de la tradición clásica, imperial y tardía.

Por otra parte, Fortunato se constituyó en uno de los modelos que fueron tenidos en cuenta como huellas directas y explícitas de la literatura que habría de surgir en poco tiempo, la del universo carolingio, ya que por gozar de una posición fronteriza entre la Antigüedad tardía y el Medioevo ${ }^{59}$ facilitaría la recepción de su obra en los siglos venideros. Queda entonces por seguir investigando si la poética de la sinceritas que le atribuye Levine es parte de la ilustrada mentalidad retórica que gozaba este vir Italus (Levine, 2008: 93), o bien Fortunato representa el punto de partida de la poesía trovadoresca que osciló entre la vanagloria de lo secular y la idealización espiritual. 


\section{Notas}

Cf. Bodelón (2013-2014: 99). El autor afirma que en Ceneta había un antiguo castellum donde los ostrogodos se habían hecho fuertes contra la invasión bizantina de Narsés, quien acude a Italia hacia el año 538 y acaba anexando el territorio itálico a Bizancio en el 555. Poco después, al producirse la invasión de los lombardos, se pierde todo rastro de Ceneta, cuyos habitantes se habrían trasladado a Duplavis. (En página 14.)

6 En torno de esta región del norte de Italia, se señala que Ceneta fue una de las localidades devastadas por Atila en su arremetida tras un breve período de tregua, infructuosas embajadas y alianzas diplomáticas, a partir del año 452. En esa ocasión embistió con su ejército las ciudades de Aquilea, Milán y Pavía, y obligó al emperador Valentiniano III a abandonar Rávena para refugiarse en Roma. Ceneta, donde Augusto había establecido una fortificación (castrum Cenetense), fue nuevamente fortificada por Teodorico, rey de los ostrogodos. Al respecto, cf. Azzara (2004: 66), Delaplace (2015: 205-206). (En página 14.)

9 Pejenaute Rubio (2004: 205) afirma que, según lo señalado por parte de la crítica, el itinerario descripto por Fortunato en la carta dirigida a Gregorio de Tours, "a quien dedica la primitiva colección de sus Carmina”, no demuestra que estaba en las primeras intenciones del poeta visitar al santuario de Martín de Tours. Más adelante en su artículo, pp. 219 ss., el autor se refiere a la posibilidad de que el viaje-peregrinación a la tumba del santo no fuera más que un pretexto por el hecho de estar involucrado en el conflicto de "los Tres Capítulos", o porque Fortunato era un embajador del emperador de Bizancio en tierras de Austrasia; no obstante la crítica descarta por completo esta última razón. (En página 14.)

10 Particularmente el poema que inaugura el L. I está dedicado a Vital, que se lo identifica como obispo de Altinum; en cuanto al segundo poema evoca y celebra la edificación del templo. (En página 14.)

13 La autora señala que, bajo el Imperio, las orationes de agradecimiento que durante la República romana se habían tributado a los senadores, se transformaron en la actio gratiarum destinada a los emperadores, que adquirió un lugar prominente en el ceremonial imperial. Como el Imperio creció y se complejizó el ceremonial, la oratoria epidíctica se tornó sumamente importante. (En página 14.)

14 Fort., 3.9.45-46: Si tibi nunc avium resonant virgulta susurro, / has inter minimus passer amore cano. ("Si ahora resuenan para ti las enramadas con el susurro de las aves, / entre estas, yo canto como un humilde gorrión"). Este poema de carácter hímnico está dedicado al obispo de Nantes, a cuya figura nos referiremos más adelante, para celebrar, en la mañana de Pascuas, el bautismo de unos sajones recién convertidos. El poeta canta la resurrección de Cristo y, como consecuencia, la de la naturaleza toda, a la cual los pájaros también celebran; Fortunato se inscribe en la tradición prudenciana de celebración de la venida de Cristo al comenzar el día (Cath. 1.13-16), pero exalta su condición de humilde cantor de la vida y la luz resurgidas. (En página 14.) 


\section{Q Bibliografía}

» Azzara, C. (2004). Las invasiones bárbaras. Granada-Valencia, Universidades de Granada y Valencia.

" Bodelón, S. (2013-2014). “Venancio Fortunato y las letras en el Medioevo y el Humanismo”, Tiempo y sociedad, 13, pp. 98-160.

"Delaplace, Ch. (2015). La fin de l'Empire romain d'Occident. Rome et les Wisigoths de 382 à 531. Rennes, Presses Universitaires de Rennes.

» George, J. (1995). Venantius Fortunatus: Personal and Political Poems, Liverpool, Liverpool University Press.

" George, J. (1998). "Venantius Fortunatus: Panegyric in Merovingian Gaul”, en Whitby, M. (ed.) The Propaganda of power. The Role of Panegyric in Late Antiquity. Leiden-BostonKöln, Brill, pp. 225-245.

» Hamman, A. (1986). “El nuevo rumbo del siglo IV”, en Di Berardino, A.-Quasten, J. (ed.) Patrología III. Madrid, BAC, pp. 3-37.

"Jones, A. E. (2009). Social mobility in Late Antique Gaul. Strategies and opportunities for the non-elite, Cambridge, Cambridge University Press.

" La Rocca, C. (2005). “Venanzio Fortunato e la società del VI secolo”, en Gasparri, S. (ed.). Alto Medioevo mediterraneo, Firenze, Firenze University Press, pp. 145-167.

»Levine, R. (2008). "Patronage and Erotic Rhetoric in the Sixth Century: The Case of Venantius Fortunatus", en Classen, A. (ed.) Words of Love and Love of Words in the Middle Ages and the Renaissance. Tempe, ACMRS, pp. 75-93.

»Pejenaute Rubio, F. (2004). "Venancio Fortunato y su marcha de Italia: las debatidas razones de un viaje sin retorno", Helmántica, Vol. 54-55, № 157, pp. 189-223.

» Roberts, M. (2012 [2009]). The Humblest Sparrow. The Poetry of Venantius Fortunatus. Ann Arbor, The Michigan University Press.

»Ware, C. (2012). Claudian and the Roman Epic Tradition. New York, Cambridge University Press.

»Williams, C. (ed., trans. \& comm.) (2004). Martial. Epigramms, Book Two. Oxford, Oxford University Press.

»Wood, I. (1994). The Merovingan Kingdoms, 450-751, New York, Longman.

\section{Fuentes literarias}

»Pucci, J. (trans., introd. and comm.) (2010). Venantius Fortunatus, Poems to Friends. Indianapolis/ Cambridge.

» Reydellet, M. (ed.) (2002). Venance Fortunat. Poèmes. Livres I-IV, Paris, Les Belles Lettres.

» Roberts, M. (ed. and trans.) (2017). Venantius Fortunatus. Poems. London, Harvard University Press. 